\title{
A ARBORIZAÇÃO DO CEMITÉRIO MUNICIPAL SÃO JOÃO BATISTA NO MUNICÍPIO DE PRESIDENTE PRUDENTE - SP
}

\author{
Letícia Aparecida Costa ${ }^{1}$, Patrícia Alexandra Antunes ${ }^{2}$, Paulo Antonio da Silva ${ }^{3}$ \\ ${ }^{1}$ Universidade do Oeste Paulista - UNOESTE, Mestrado em Meio Ambiente e Desenvolvimento Regional, Presidente \\ Prudente, SP. Agência de fomento: CAPES. E-mail: le_costa93@ hotmail.com.
}

\section{RESUMO}

Nas cidades encontramos diversos problemas relacionados à supressão da vegetação, por isso a arborização urbana é fundamental para promover equilíbrio ambiental e mental da população. Os cemitérios localizados nos centros urbanos são visitados frequentemente pela população e nas últimas décadas começaram a ser considerados como fontes causadoras de impacto ambiental. 0 objetivo deste trabalho é apresentar a vegetação existente no interior do cemitério São João Batista, seus problemas e os impactos que algumas espécies provocam neste ambiente. Para o desenvolvimento da pesquisa realizou-se um levantamento bibliográfico, e trabalhos de campo, verificando as espécies plantadas na área e os impactos decorrentes dessa atividade. Considera-se que a vegetação dos cemitérios ocasionam impactos ambientais positivos e negativos e que é preciso um estudo para a escolha das espécies a serem plantadas. Foi possível concluir que a arborização do cemitério foi realizada de forma incorreta, devido à falta de planejamento.

Palavras-chave: vegetação, planejamento, atividade cemiterial, impacto socioambiental.

\section{INAPPROPRIATE AFFORESTATION IN THE MUNICIPAL CEMETERY SÃO JOÃO BATISTA OF PRESIDENTE PRUDENTE CITY, SÂO PAULO STATE}

\begin{abstract}
In the cities we find several problems related to the removal of vegetation, so the urban trees are the key to promoting environmental balance and mental population. Cemeteries located in urban centers are often visited by the population and in recent decades became sources causing environmental impact. The objective of this paper is to present the existing vegetation in the interior of São João Batista cemetery, it problems and the impact that some species cause in this environment. For the development of research we carried out a literature review, and field work, verifying the species planted in the area and the impacts of this activity. It is considered that the vegetation in cemeteries causes positive and negative environmental impacts and it takes a study for the choice of species to be planted. It was concluded that the trees of the cemetery was carried out incorrectly due to lack of planning.
\end{abstract}

Keywords: vegetation, planning, cemeterial activity, social and environmental impact . 
INTRODUÇÃO

A vegetação possui um papel fundamental em relação ao clima e uma série de serviços ambientais que presta ao homem, e sua supressão impacta de forma negativa o ambiente em que se localiza. Com a supressão da vegetação ocorre a redução do controle climático, o aumento da poluição do ar e acústica, a perda da qualidade estética. Por outro lado, com a presença da vegetação há um aumento dos efeitos benéficos sobre a saúde mental e física da população, aumento do conforto ambiental, valorização de áreas para convívio social, valorização econômica das propriedades e formação de uma memória e de um patrimônio cultural (VARJABEDIAN, 2002). Nas cidades encontramos diversos problemas relacionados à sua supressão, por isso a arborização urbana é fundamental para promover equilíbrio ambiental e mental da população, que circula pelas cidades e especialmente às que visitam os cemitérios.

A palavra cemitério tem sua origem grega "KOUMETERIAN", e seu significado é onde eu durmo. Com a chegada do cristianismo, o termo ganhou um novo sentido como sendo um local destinado ao repouso final após a morte (LELI et al.,2012). Nas últimas décadas os cemitérios começaram a ser considerados como fontes causadoras de impacto ambiental e não apenas como um local onde os vivos prestavam homenagens aos seus entes queridos (BOCCHESE, PELIZZARO, BOCCHESE, 2007). Com as alterações que ocorrem no meio ambiente através da instalação dos cemitérios, podemos considerar que esta atividade polui e contamina o meio.

A presença de vegetação e animais nos cemitérios pode amenizar o local hostil que ele representa para muitas pessoas, e de acordo com Pacheco (2012), a existência de vegetação nos cemitérios e seu entorno é salutar. Para além da aparência estética, é importante sob o ponto de vista higiênico e sanitário. Purifica o ambiente e, além disso, oxigena o solo e o subsolo, apresentando uma atuação benéfica no desenrolar do ciclo evolutivo ou de modificação da matéria orgânica.As árvores a serem plantadas devem se situar nas zonas mais afastadas das sepulturas, sendo minuciosamente escolhidas de modo a se obter o mais perfeito efeito arquitetural, como o da salubridade (PACHECO, 2012).

O objetivo deste estudo foi apresentar a vegetação existente no interior do cemitério São João Batista - CSJB, seus problemas e os impactos que algumas espécies provocam neste ambiente.

\section{METODOLOGIA}

O município de Presidente Prudente está localizado no oeste do estado de São Paulo. Pertencente à mesorregião e microrregião de mesmo nome, localiza-se no interior da capital do 
estado, distando desta cerca de $560 \mathrm{~km}$. Ocupa uma área de 562,107 Km², sendo que 16,5600 Km² estão em perímetro urbano (PREFEITURA MUNICIPAL, 2015).

Para o desenvolvimento da pesquisa realizou-se um levantamento bibliográfico, evidenciando o tipo de vegetação no cemitério, e trabalhos de campo, verificando as espécies plantadas na área e os impactos decorrentes dessa atividade. Após o levantamento bibliográfico e trabalho de campo realizado, foi possível identificar os impactos ambientais em relação à vegetação que o cemitério São João Batista vem sofrendo.

\section{RESULTADOS}

O cemitério São João Batista está localizado em área urbana da cidade, na Rua José Bongiovani, $\mathrm{n}$ 0 975, Vila Liberdade, ocupando uma área de aproximadamente $182.000 \mathrm{~m}^{2}$. A Figura 1 apresenta a vista aérea do cemitério São João Batista.

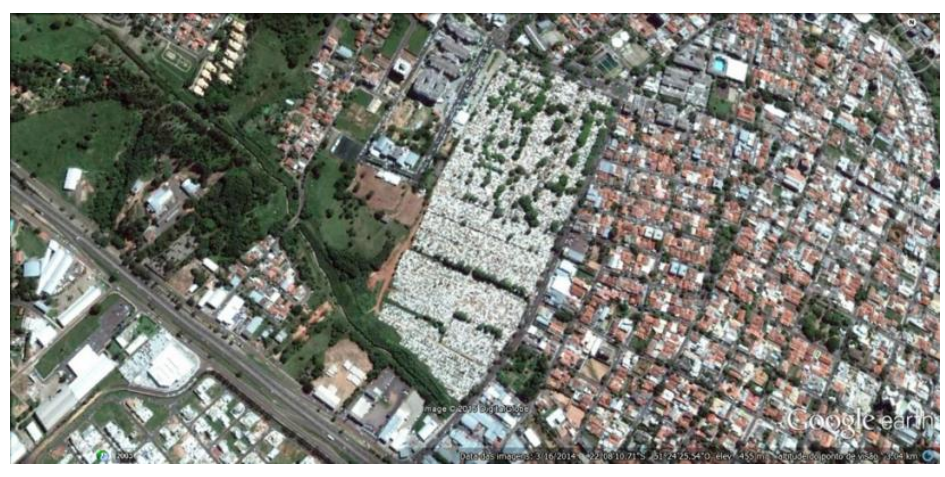

Figura 1. Cemitério São João Batista

Fonte: Google Earth, 2014.

O local tem seus primeiros registros datados de junho de 1937. Calcula-se que mais de 83 mil pessoas tenham sido sepultadas no local que tem mais de 19 mil túmulos. Entre os anos de 2003 a 2013 foram sepultados 12.583 cadáveres, conforme apresentado no Quadro 1. O Quadro 1 elucida a quantidade de sepultados de cada sexo, a faixa etária, o total de sepultamentos durante o período de 2003 a 2013, no total dos 10 anos separados pelos meses de janeiro a dezembro. 
QUADRO 1. Totais de sepultamentos no cemitério entre os anos de 2003 e 2013

\begin{tabular}{|c|c|c|c|c|c|c|c|c|c|c|c|c|}
\hline Anos & \multicolumn{10}{|c|}{ Anos de 2003 a 2013} \\
\hline & jan & fev & mar & abr & mai & jun & jul & ago & set & out & nov & dez \\
\hline $\begin{array}{c}\text { Total } \\
\text { masculino }\end{array}$ & 608 & 545 & 612 & 570 & 603 & 669 & 707 & 621 & 574 & 584 & 518 & 612 \\
\hline $\begin{array}{c}\text { Total } \\
\text { feminino }\end{array}$ & 441 & 386 & 453 & 436 & 431 & 505 & 466 & 513 & 446 & 430 & 424 & 429 \\
\hline $\begin{array}{c}\text { Até 12 } \\
\text { anos }\end{array}$ & 55 & 49 & 63 & 44 & 59 & 47 & 52 & 42 & 46 & 54 & 46 & 45 \\
\hline $\begin{array}{c}\text { Até 21 } \\
\text { anos }\end{array}$ & 13 & 12 & 16 & 19 & 15 & 17 & 18 & 16 & 13 & 18 & 14 & 20 \\
\hline $\begin{array}{c}\text { Até 60 } \\
\text { anos }\end{array}$ & 319 & 276 & 302 & 278 & 265 & 301 & 311 & 295 & 292 & 279 & 276 & 294 \\
\hline $\begin{array}{c}\text { Mais de } \\
\mathbf{6 0} \text { anos }\end{array}$ & 663 & 593 & 682 & 661 & 694 & 809 & 792 & 779 & 668 & 662 & 605 & 682 \\
\hline Totais & $\mathbf{1 . 0 5 0}$ & $\mathbf{9 3 0}$ & $\mathbf{1 . 0 6 3}$ & $\mathbf{1 . 0 0 2}$ & $\mathbf{1 . 0 3 3}$ & $\mathbf{1 . 1 7 4}$ & $\mathbf{1 . 1 7 3}$ & $\mathbf{1 . 1 3 2}$ & $\mathbf{1 . 0 1 9}$ & $\mathbf{1 . 0 1 3}$ & $\mathbf{9 4 1}$ & $\mathbf{1 . 0 4 1}$ \\
\hline
\end{tabular}

Fonte: Prefeitura Municipal de Presidente Prudente, 2014.

A arborização do cemitério pode ser dividida em duas fases, conforme foi à forma de implantação. A parte mais antiga inicia-se na Rua José Bongiovani e encerra no divisor de águas do córrego do Veado. A parte mais recente vai do divisor de águas do córrego do Veado até a vertente do córrego Ferreirinha. Na Figura 2 é possível observar algumas árvores da espécie Tipuana (Tipuana Tipu), que são de grande porte quebrando o calçamento do cemitério. 


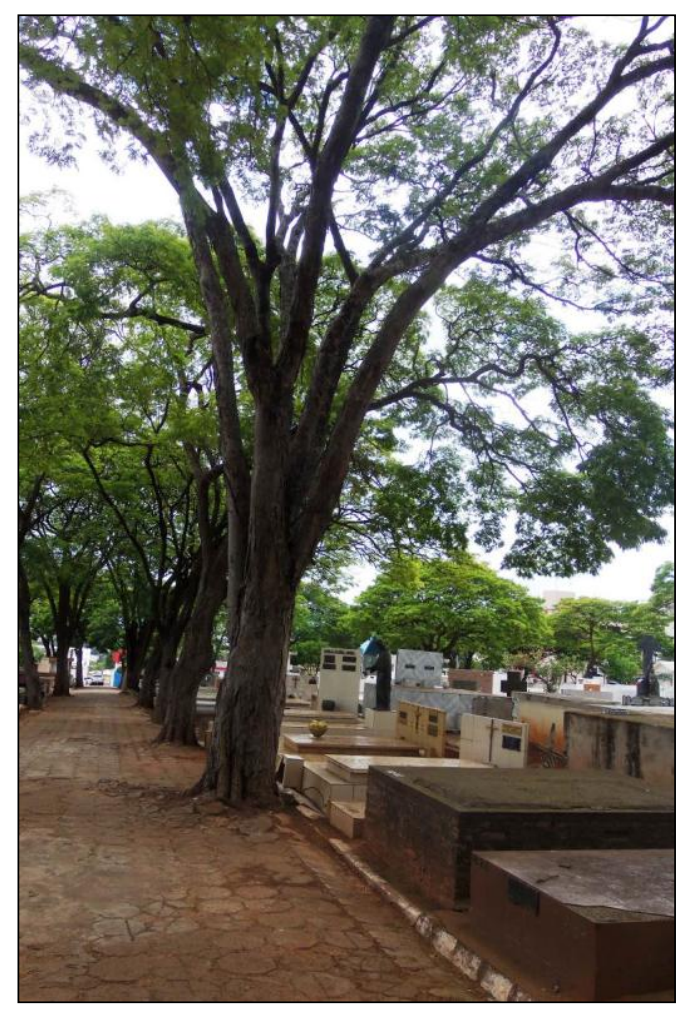

Figura 2. Tipuana no cemitério São João Batista Fonte: COSTA, 2014

A Figura 3 evidencia uma área sem vegetação, mas ao fundo da figura é possível notar uma extensa fileira de árvores, mostrando que a arborização foi feita sem um planejamento adequado.

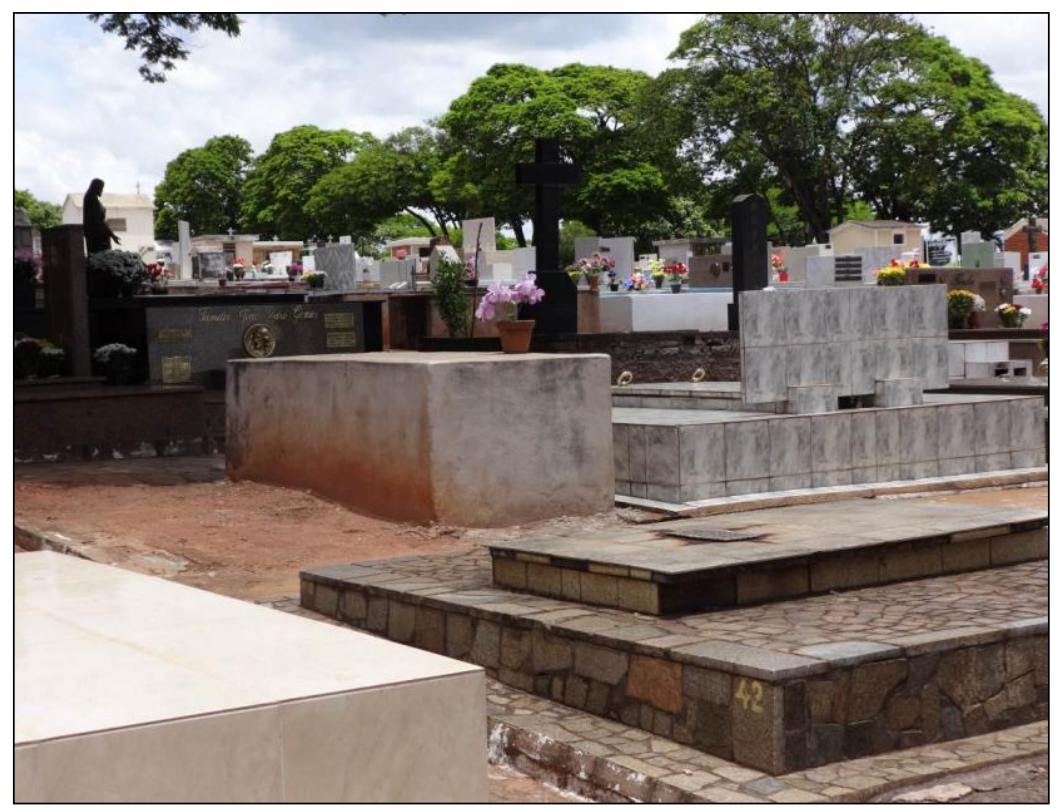

Figura 3. Área do cemitério com irregularidades entre área sem vegetação e vegetadas Fonte: COSTA, 2014

Na Figura 4 podemos perceber uma rua central do cemitério, onde tem muitas árvores, propiciando uma área extensa de sombra para os visitantes. 


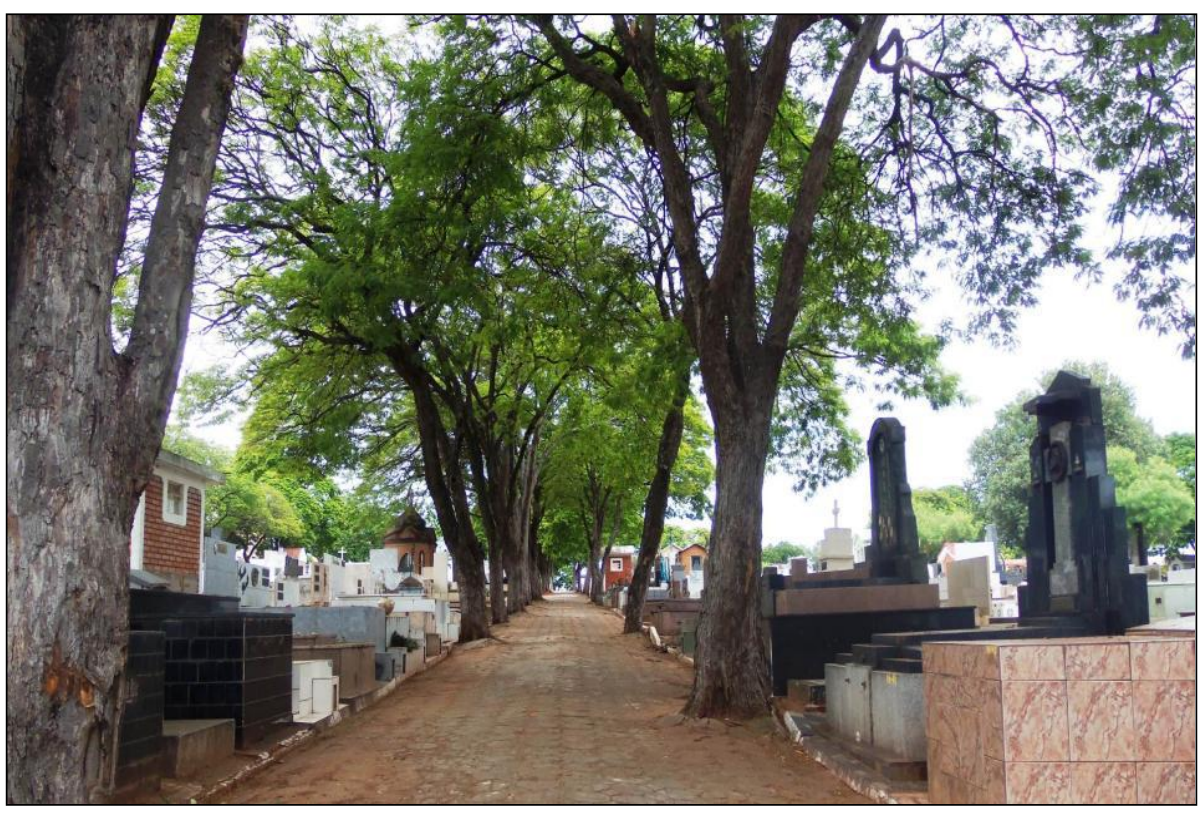

Figura 4. Área bem arborizada do cemitério Fonte: COSTA, 2014

Na Figura 5 é possível observar a parte mais nova do cemitério, onde as espécies escolhidas para serem plantadas foram principalmente a espécie Murraya paniculata Sin, popularmente conhecida como murta, e oiti (Licania tomentosa).

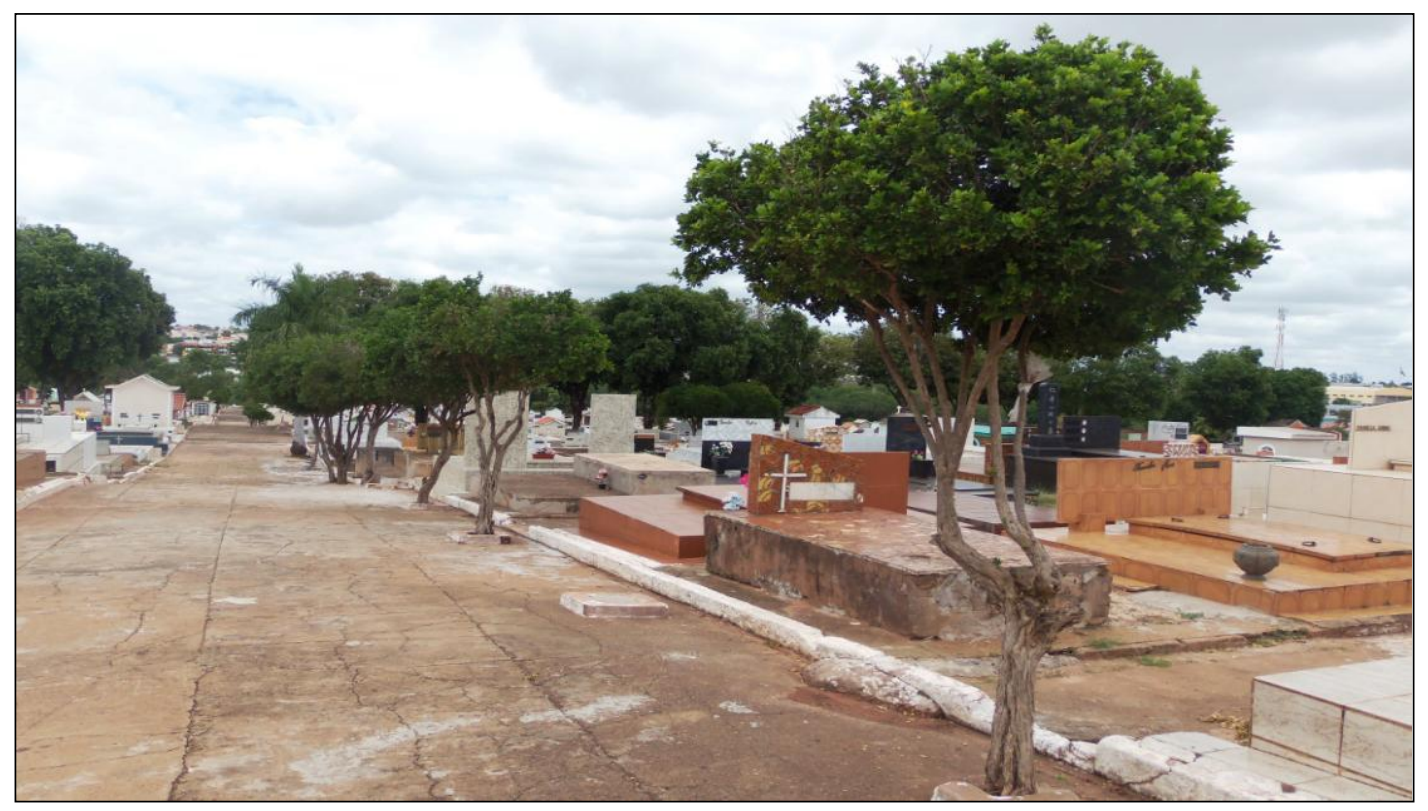

Figura 5. Área com predominância de uma única espécie Fonte: COSTA, 2014 
Na Figura 6 é visível que a área de preservação permanente (APP) se encontra desmatada e desprotegida. Alguns túmulos estão dentro da área de 30 metros que deveria ser a APP, que segundo a legislação não é permitido.

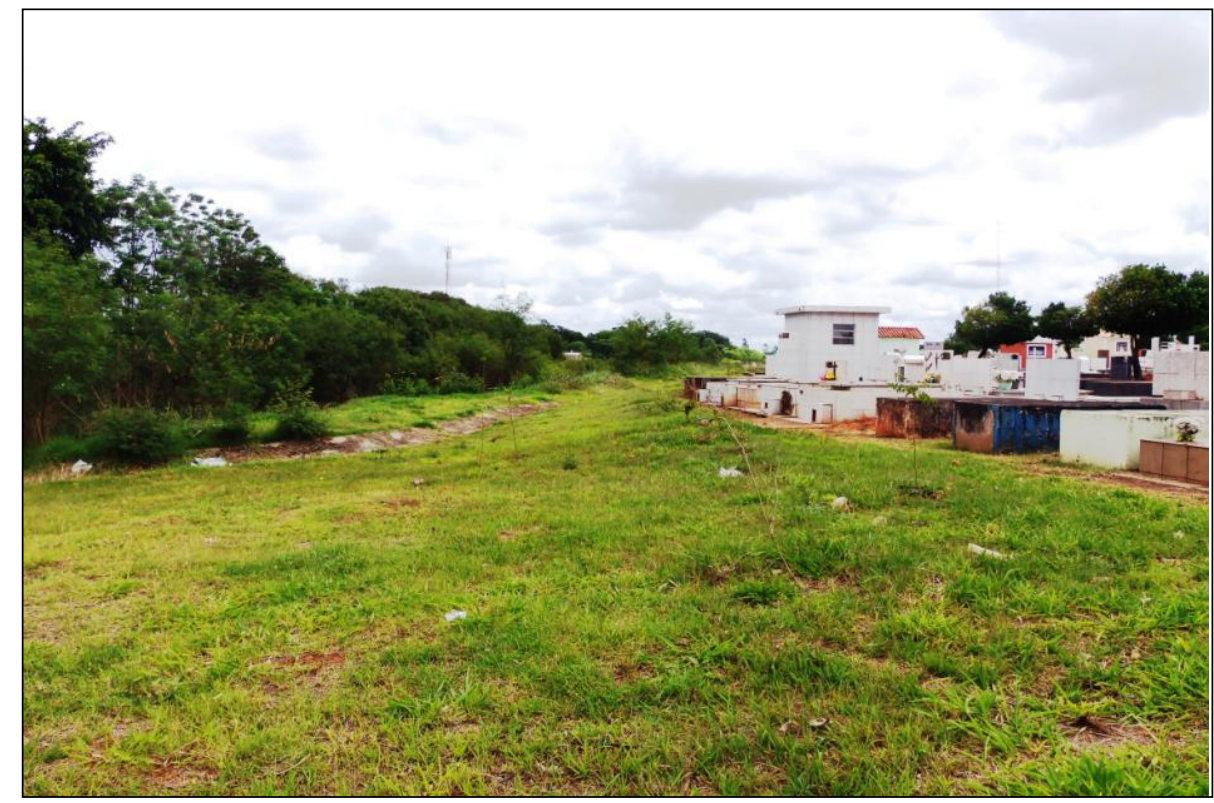

FIGURA 6. Área de APP sendo ocupada por túmulos

Fonte: COSTA, 2014

\section{DISCUSSÃO}

Considera-se que a vegetação dos cemitérios ocasionam impactos ambientais positivos e negativos. No interior do cemitério é observado que a vegetação existente é composta de espécies exóticas e localiza-se, principalmente na área antiga, provocando danos nos túmulos através das raízes das árvores e pela infiltração de água nos túmulos, mas também proporciona um conforto térmico, visto que as árvores proporcionam abrigo do sol.

Na área mais recente do cemitério, os problemas afetam o equilíbrio ecológico da área e geram a falta de conforto térmico aos visitantes, pois torna o local muito quente. Tendo em vista que as plantas são a base da cadeia alimentar, portanto, uma das promotoras da diversidade de organismos. Parte-se do pressuposto de que um ambiente rico em espécies vegetais contribui à manutenção de diversos elementos da fauna, além de favorecer a estética (ALVEY, 2006) e diminuir a hostilidade local aos visitantes. Intuitivamente, quanto mais homogênea for a paisagem local (e.g., grande densidade de uma única espécies), menor é a probabilidade de que o ambiente seja biodiverso (ALVEY, 2006), portanto, de pouco valor estético e recreativo (COSTANZA et al., 1997). 


\section{CONCLUSÃO}

Foi possível concluir que a arborização do cemitério São João Batista foi realizada de forma incorreta e sem planejamento. Na área mais antiga do cemitério encontram-se árvores grandes e robustas, e com longas raízes de idades que atingem entre 20 a 50 anos, sendo as mais comuns às espécies Sibipiruna (Caesalpinia Peltophoroides) e Tipuana (Tipuana Tipo). Espécies estas que em face do porte e da idade apresentam dificuldade de locomoção para a população e danos aos túmulos, mas que também acabam trazendo alguns benefícios como a sombra que proporciona para os visitantes. Já na parte mais recente do cemitério existe um déficit da vegetação, onde a maior parte das espécies arbóreas são oiti e murta, e muitas quadras não possuem nenhuma espécie de árvores, desfavorecendo o equilíbrio ecológico da área.

\section{REFERÊNCIAS}

ALVEY, A. A. Promoting and preserving biodiversity in the urban forest. Urban Forestry \& Urban Greening, v.5, n.4, p.195-201, 2006. http://dx.doi.org/10.1016/j.ufug.2006.09.003

BOCCHESE; PELLIZZARO; BOCCHESE. Problemas ambientais decorrentes do cemitério municipal de Pato Branco-PR. Geoambiente On-line, n.9, p.01-1, 2007.

COSTANZA, R. et al. The value of the world's ecosystem services and natural capital. Nature, USA, v.387, p.253-260, mai. 1997.

LELI, I. T; et al. Estudos ambientais para cemitérios: indicadores, áreas de influência e impactos ambientais. Boletim de Geografia, v.30, n.1, p.45-54, 2012. http://dx.doi.org/10.4025/bolgeogr.v30i1.16348

PACHECO, A. Meio Ambiente e Cemitérios, São Paulo: Editora Senac São Paulo, 2012.

VARJABEDIAN R. Ambiente Urbano e Áreas Verdes, Centro de Apoio Operacional das Promotorias de Justiça de Meio Ambiente. 2002. 